\title{
El esquema de vacunación de Costa Rica
}

\section{Oscar Porras-Madrigal ${ }^{1}$}

El sistema de salud de Costa Rica ofrece un esquema de vacunación amplio, técnicamente diseñado, basado en evidencia y apoyado en literatura y recomendaciones internacionales. Estas guías que ofrece Acta Médica Costarricense permiten al médico o al personal de salud que aplica vacunas una orientación sobre edad de aplicación, dosis, vía de aplicación y refuerzos producto del acuerdo entre el Ministerio de Salud, la Caja Costarricense de Seguro Social y la Asociación Costarricense de Pediatría.

Para facilitar el uso del esquema se ha dividido en las edades de vacunación básica y refuerzos. Además se hace una distinción entre las vacunas que se encuentran en el esquema oficial del Ministerio de Salud y la Caja Costarricense de Seguro Social y que están disponibles en los EBAIS y clínicas, y vacunas que están recomendadas pero que se deben adquirir en farmacias para que sean aplicadas, por no estar incluidas dentro de los servicios que ofrece el sistema de salud pública.

Las vacunas deben ser aplicadas por personal capacitado que después de una historia clínica adecuada que identifique contraindicaciones y que pueda explicar a los padres y madres lo que se espera de la vacuna, sus efectos adversos y las incomodidades que pueda producir en los días siguientes a la aplicación.

\begin{tabular}{|c|c|c|c|c|c|c|c|c|c|c|c|c|c|}
\hline $\begin{array}{l}\text { Edad } \Rightarrow \\
\text { Vecuna } \gamma\end{array}$ & $\begin{array}{l}\text { Aocien } \\
\text { Nacido }\end{array}$ & $\begin{array}{c}2 \\
\text { mosos } \\
\end{array}$ & $\begin{array}{c}4 \\
\text { meses } \\
\end{array}$ & $\begin{array}{c}6 \\
\text { mosos } \\
\end{array}$ & $\begin{array}{c}12 \\
\text { mess }\end{array}$ & $\begin{array}{c}15 \\
\text { meses }\end{array}$ & $\begin{array}{c}18 \\
\text { meses } \\
\end{array}$ & $\begin{array}{c}24 \\
\text { mosos } \\
\end{array}$ & $\begin{array}{c}30 \\
\text { moses } \\
\end{array}$ & $\begin{array}{c}4 \\
\text { anics } \\
\end{array}$ & $\begin{array}{l}6 \text { a } 7 \\
\text { ahios }\end{array}$ & $\begin{array}{c}11 \text { a } 12 \\
\text { ahos } \\
\end{array}$ & $\begin{array}{c}14 \text { a 19 } \\
\text { años }\end{array}$ \\
\hline Tuberailosis $\{B O G$ \} & $B C 0$ & & & & & & & & & & & & \\
\hline Hopatitis $\mathrm{B}\{\mathrm{HNB}\}^{\mathrm{N}}$ & 130.4 & Hon:2 & & 413.8 & & & & & & & & HNB $6 \mathrm{R}$ & \\
\hline $\begin{array}{l}\text { Diteria Tosferina } \\
\text { Tadance (DPT) }\end{array}$ & & $\mathrm{L} 9 \mathrm{r} / 3$ & LPY: & Dera & & & L9: 138 & & & arses & & & \\
\hline DHeia-Tetonos (dI) & & & & & & & & & & & & & B! \\
\hline $\begin{array}{l}\text { Haemophitus idluenzas } \\
\text { tipo } \mathrm{B} \text { (HiB) }\end{array}$ & & 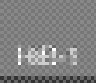 & $412 z$ & Hith:3 & & & $H: A 3 \mathrm{~A}$ & & & & & & \\
\hline Polio orel (PQNY & & mav-1 & $\operatorname{mos} 2$ & mov.s & & & & & & Posift & & & \\
\hline $\begin{array}{l}\text { SarampiónRuboda } \\
\text { Paporas (SAP) }\end{array}$ & & & & & & $\mathrm{s}+\mathrm{P}$ & & & & & SRP-18 & & $58 P \cdot 4:$ \\
\hline Varicela (MARY) & & & & & WAR & & & & & & & VAR-1R & \\
\hline Hapstis is A $\langle\text { HWA }\}^{\text {d }}$ & & & & & & & & HVA-1 & HWA.2 & & & & \\
\hline
\end{tabular}

Jefe Servicio de Inmunología, Hospital Nacional de Niños: "Carlos Sáenz Herrera".

Correspondencia: Oscar Porras Madrigal. Apdo. 1654-1000 San José, Cos-

ta Rica. Correo electrónico: oporrasm@cariari.ucr.ac.cr 


\section{Notas}

a Los niños (as) que nacen de madres positivas para el antígeno de superficie del virus de Hepatitis B, deben recibir la vacuna de Hepatitis B y $0,5 \mathrm{ml}$ de Inmunoglobulina contra el virus de Hepatitis B dentro de las primeras 12 horas de edad, aplicadas en sitios diferentes

b En la vacuna difteria-tosferina-tétanos, el componente para tosferina (B. pertussis) está disponible en dos opciones: macerado de B. pertussis (DPT) y componente acelular (DpaT). La opción acelular solamente está disponible en las farmacias fuera del Sistema de Salud Pública.

c Existen opciones de vacuna de polio que se aplica por via subcutánea, en los que el componente es virus muerto de polio. Esta opción se encuentra disponible como vacunas combinadas con DPT-HiB o DPaT-HiB.

d Las vacunas contra Varicela y Hepatitis A, no están disponibles en el Sistema de Salud Pública.

\section{Referencias}

1. American Academy of Pediatrics. Active and passive immunization. En:Pickering LK, ed. 2000 Red book: report of the committee on infectious diseases. 25 ed. Elk Grove Village, IL: American Academy of Pediatrics 2000; 1-81.

2. Centers for Disease Control and Prevention. National Immunization Program. 2001. Disponible en: URL: http://www.cdc.gov/nip/

3. Ministerio de Salud de Costa Rica. Esquema de vacunación Costa Rica. 2001. Disponible en: URL:

http://www.medicos.sa.cr/GENERAL/esquema.htm

4. American Academy of Pediatrics. Immunization protects children: 2001 immunization schedule. 2001.

Disponible en URL: http://www.aap.org/family/parents/immunize.htm

5. National Partnership for Immunization. NPI reference guide on vaccines and vaccine safety. 2001. Disponible en URL:

http://www.partnersforimmunization.org/guidebook.html 